Spinal Metastasis Treated with Percutaneous Radiofrequency Ablation and Vertebroplasty in A Day

\title{
Care Treatment: A Case Report and Review of The Literature
}

\section{Waluyo Sugito1, ${ }^{\text {* }}$, Jelle Overbosch ${ }^{2, \S}$, D.L.M. Oterdoom ${ }^{3, \S}$, Thomas C. Kwee ${ }^{2, \S}$ and Paul C. Jutte ${ }^{1, \S}$}

${ }^{1}$ Department of Orthopaedic, University Medical Center Groningen, University of Groningen, the Netherlands ${ }^{2}$ Department of Radiology, University Medical Center Groningen, University of Groningen, the Netherlands ${ }^{3}$ Department of Neurosurgery, University Medical Center Groningen, University of Groningen, the Netherlands

§: All authors contributed equally to this work

*Corresponding author: Sugito W, Department of Orthopaedic, University Medical Center Groningen, University of Groningen, the Netherlands Received date: 12 June 2020; Accepted date: 18 June 2020; Published date: 24 June 2020

Citation: Sugito W, Overbosch J, Oterdoom DLM, Kwee TC, Jutte PC (2020) Spinal Metastasis Treated with Percutaneous Radiofrequency Ablation and Vertebroplasty In A Day Care Treatment: A Case Report and Review of The Literature. J Med Case Rep Case Series 1(1): https://doi.org/10.38207/jmcrcs20103

Copyright: (C) 2020 Sugito W. This is an open-access article distributed under the terms of the Creative Commons Attribution License, which permits unrestricted use, distribution, and reproduction in any medium, provided the original author and source are credited.

\begin{abstract}
Case. A 74-year-old woman with renal cell carcinoma had an oligometastatic in vertebra $\mathrm{T} 7$ which was treated surgically and adjuvant radiation therapy. Nine months later, the patient reported severe back pain. CT showed a new metastasis of the vertebral body of L1. This lesion was ablatedusing percutaneous transpedicular radiofrequency ablation (RFA) in combination with the application of bone cement vertebroplasty. Percutaneoustranspedicular RFA was considered beneficial, due to being minimally invasive, possible in daycare setting and lacking the tissue damage as compared to open surgical treatment. This paper describes the perks of RFA as treatment in spinal metastasis to create awareness for this valuablealternative palliative treatment in a metastasized setting.

Conclusion. Percutaneous radiofrequency ablation in combination with the application of vertebroplasty is a potential minimal invasive option to reduce the tumor load, provide pain relieve and stabilization in day care.
\end{abstract}

Keywords: Spinal metastasis, radiofrequency ablation, vertebroplasty, day care treatment

\section{Introduction}

The vertebral body is the most common location among osseous sites for metastatic lesions, accounting for $40 \%$ of all bone metastatic lesions $[\mathbf{1 , 2}]$. Vertebral body metastasis may cause intractable pain, fractures and also spinal cord compression [3]. Intractable pain in vertebral metastasis decreases the quality of life [2]. Conventional fractionated external beam radiation therapy (EBRT) is often used as treatment for painful spinal metastasis [3]. However, $40 \%$ of patients show no pain relief $65 \%$ of patients have residual pain after EBRT

\section{Case Report}

A 74-year-old woman with previous history of renal cell carcinoma that was treated with chemotherapy and surgery had metastasis at vertebra T7. Because of progressive neurologic deficit due to spinal cord compression this metastasis was embolized and then surgically removed with circumferential stabilization in the same procedure. Surgery was followed by adjuvant radiation therapy (Figure 1). Throughout the post-operative period, chest CT scans were performed routinely to evaluate the treatment. Nine months later the patient developed severe back pain. CT (Figure 2a and 2b) and MRI (Figure 3a and 3b) showed a well demarcated lesion with low signal on both
[4]. Percutaneous radiofrequency ablation (RFA) in combination with vertebroplasty may represent a good treatment combination for palliative treatment in patients with spine metastasis. It can be beneficial for improving the quality of life of cancer patients because it offers an effective minimally invasive procedure in day care. Literature on this topic is scarce. We present arepresentative case, including a review of the literature.

T1 and T2 weighted images was seen in vertebral body L1. The posterior wall was intact. The amount of osteolysis made L1 at risk for collapse and it was decided to offer her an intervention. After discussion about the severity of the situation, the choice of intervention, the risks, and the patient expectations, RFA and vertebral augmentation was performed using CT guidance under general anesthesia in the prone position. The vertebral body was accessed using a transpedicular approach under computed tomography (CT) guidance. 


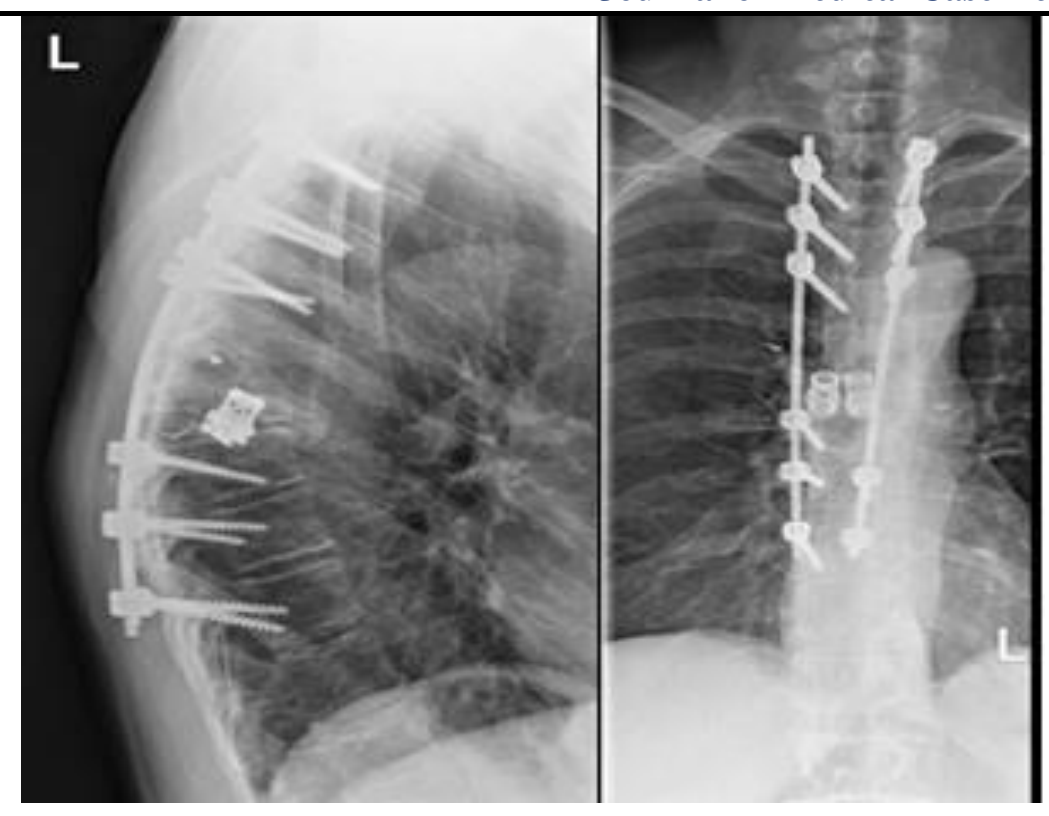

Figure 1: Previous post-operative X-ray of 74-year-old female with spinal metastasis.

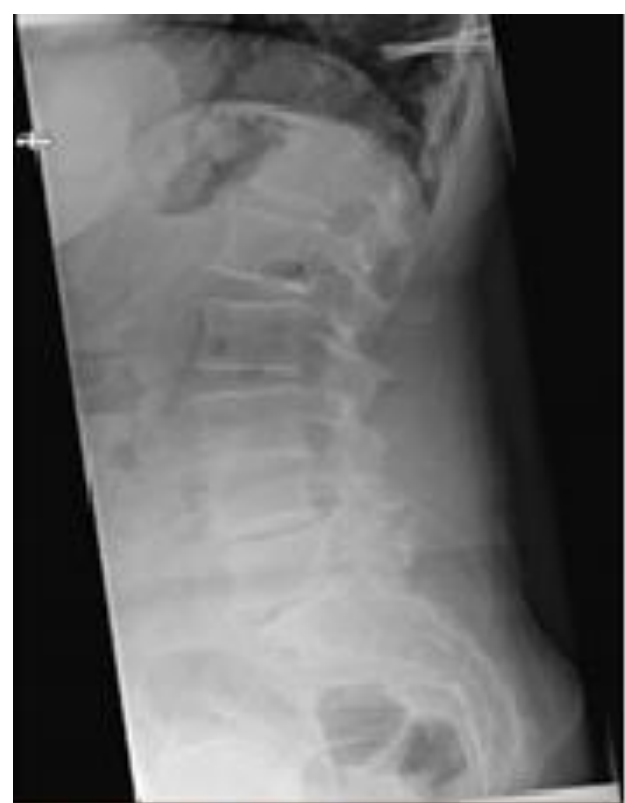

Figure 2a

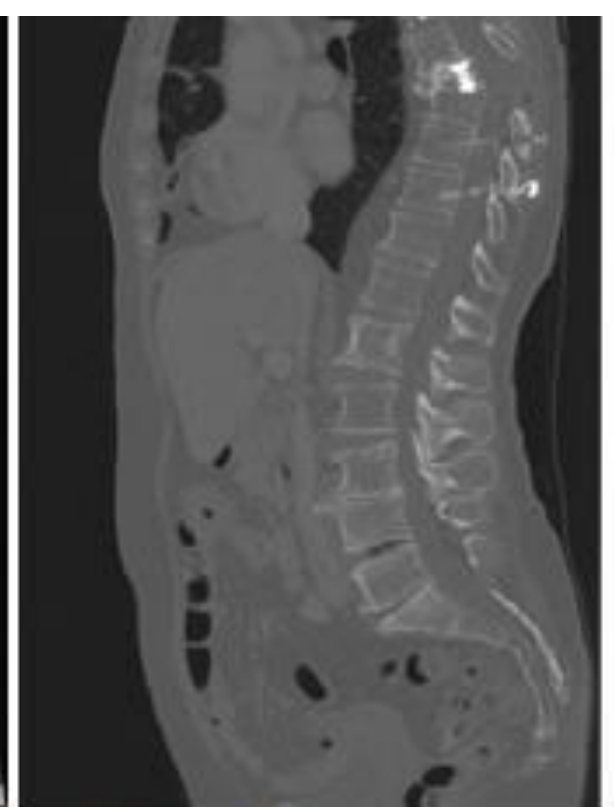

Figure 2b

Figure 2a: Lumbar spine X-ray shows a lytic lesion in vertebral body L1.

Figure 2b: CT finding of a lytic lesion in L1.

3

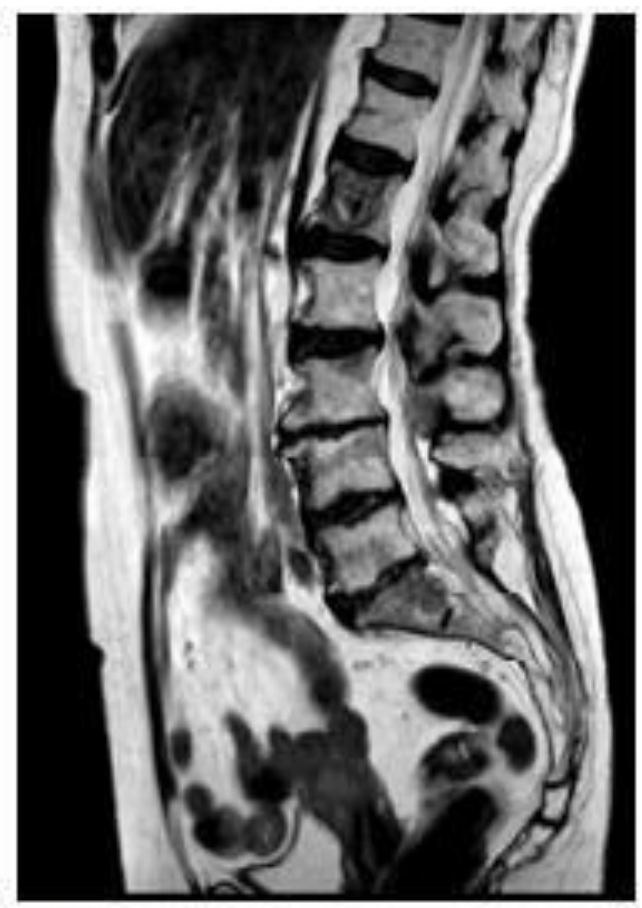

Figure 3a

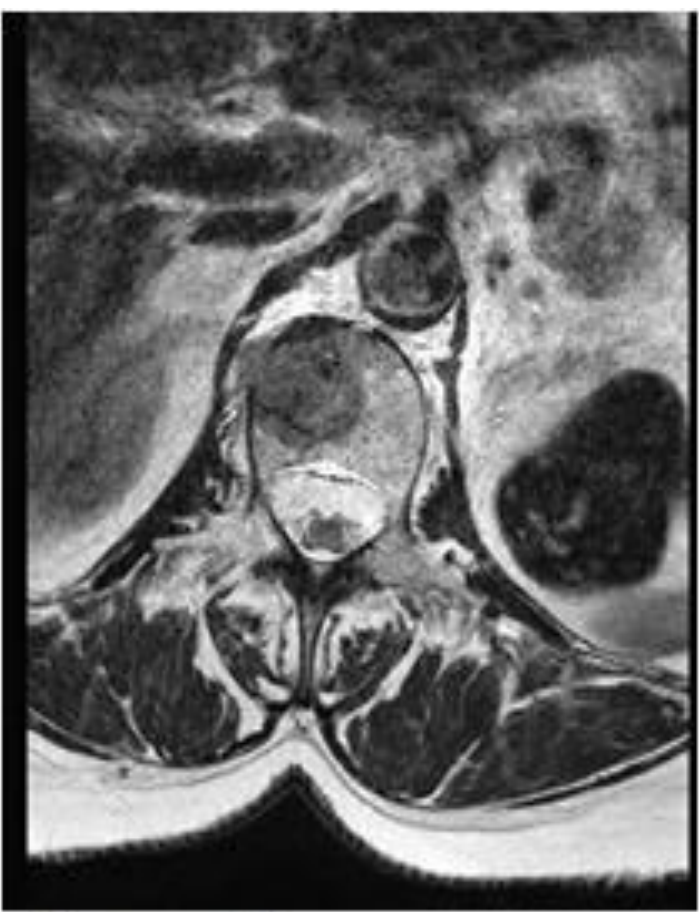

Figure 3b

Figure 3a: Preoperative sagittal T2-weighted MRI image showed a well-demarcated lesion with intact anterior and posterior column.

Figure 3b: Preoperative axial T2-weighted MRI image showed an intact posterior wall. 


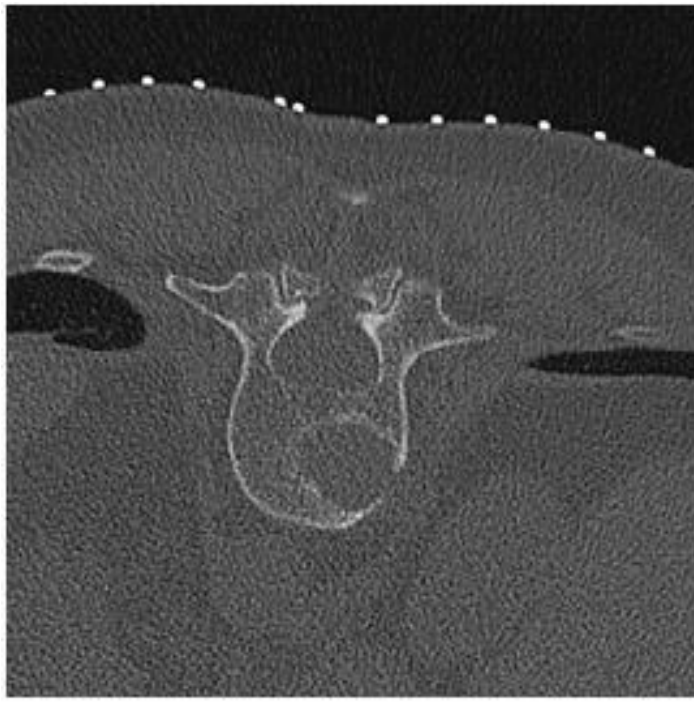

Figure 4a

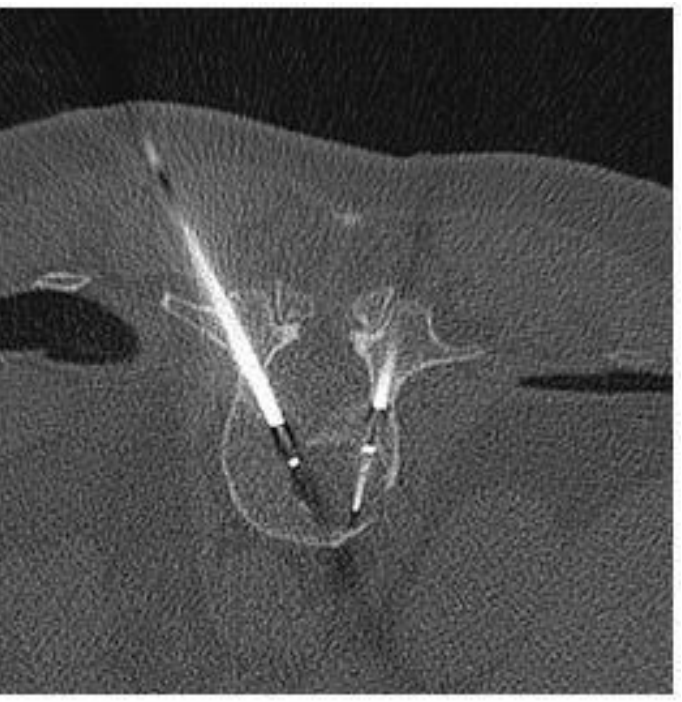

Figure 4b

Figure 4a: Placement of the skin marker at the level of L1

Figure 4b: Placement of the RFA probe in the tumor.

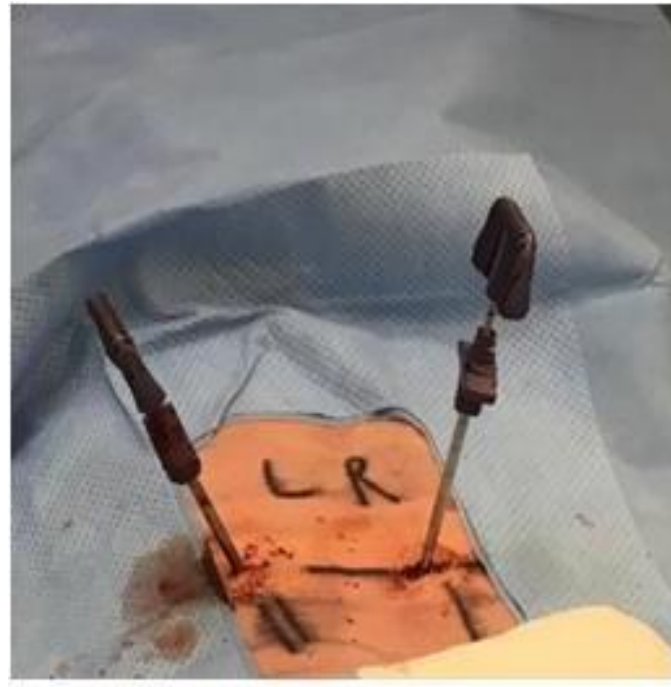

Figure 5a

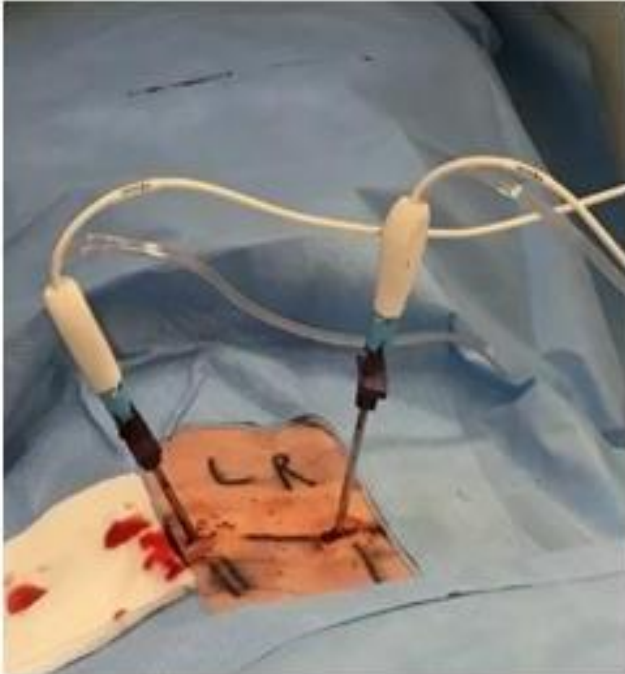

Figure 5b

Figure 5a: From the dorsal side, the vertebral body lesion was reached transpedicularly right and left.

Figure 5b: Two electrodes were boosted into the metastasis lesion through both pedicles.

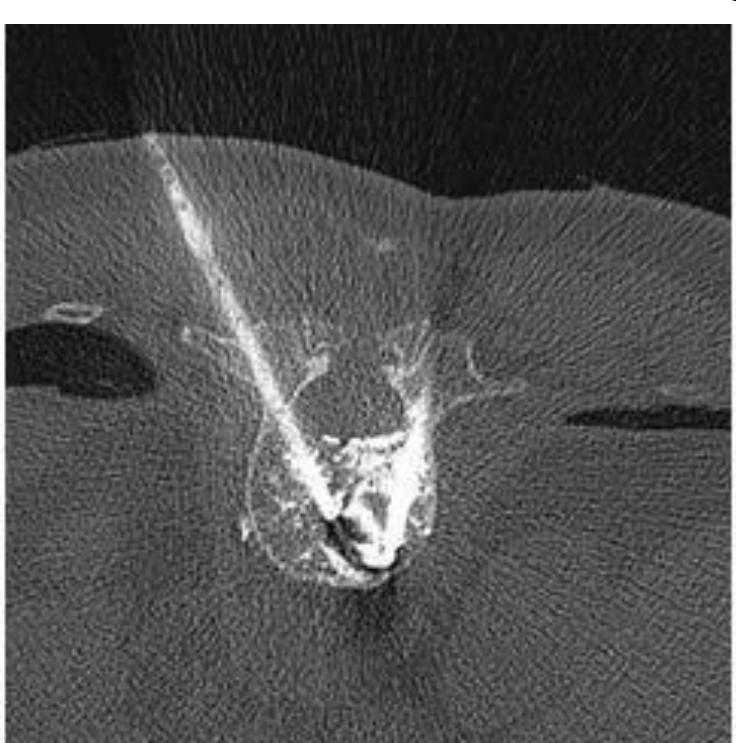

Figure 6a

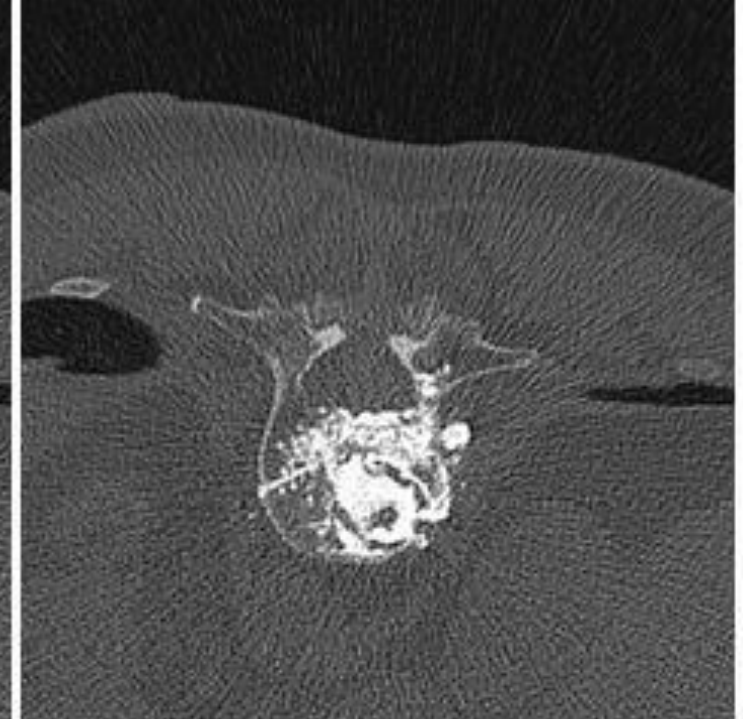

Figure 6b

Figure 6a: Intraoperative axial CT scan of injection of bone cement into the lesion.

Figure 6b: A total of $3 \mathrm{ml}$ of cement was injected that spread into the metastasis cavity, and partly also into the body of L1. Minimal cement leakage in the adjacent soft tissue.

Two RFA probes were subsequently inserted transpedicular into the appropriate location (Figures 4 and 5). Thermal energy was applied to achieve desired ablation zone using $15 \mathrm{~mm}$ tip probe, in total 11 minutes to a maximum temperature 70 degrees Celsius (reached after 4 minutes). RFA was followed by vertebroplasty via the same access cannula using polymethylmethacrylate bone cement. Good distribution of cement was achieved through the osteolytic metastatic cavity (Figure 6). There were minimal cement leaks up to adjacent soft tissue parts without any consequences. There were no complaints of back pain and no signs of local recurrence on MRI in a year follow up. 


\section{Discussion}

The spine is the most common site of osseous involvement for metastasis in cancer patients [5]. Metastatic lesions in the spineremain a challenge due to proximity of neural structures and stabilityissues (paraplegia and fracture due to destruction and collapse). Patients will develop intractable bone pain and decreased quality of life [6]. The treatment of metastatic spine lesion requires a multidisciplinary input. Treatment options not only include continually evolving medical therapy regimens, surgical techniques, and radiation technologies, but also emerging minimally invasive interventions, that may provide equally effective local control and pain relief at a lower cost in the palliative life phase of cancer patients.

RFA has been used before for minimally invasive treatment of vertebral metastasis $[3,7]$. It is performed by accessing the vertebral body under $\mathrm{CT}$ guidance to generate cytotoxic temperatures that cause tumor necrosis. RFA is a feasible treatment of spine metastasis because of short procedure times, its minimal invasiveness, and its capability to be performed on an ambulatory basis as day care treatment, so it does not hinder or delay other treatments such as chemotherapy or adjuvant radiotherapy. It does not stabilize the spine though.

Bone cement augmentation, in this case vertebroplasty, a form of percutaneous vertebral body augmentation, is often performed in patients with intractable bone pain due to lytic lesions or fractures in the vertebral bodies due to osteoporosis or tumor metastasis in which conservative therapy or radiation has failed or in lesions that require stabilization. Percutaneous injection of polymethylmethacrylate is done via percutaneously inserted needles under radiological guidance and has shown well-documented safety profile. The characteristic of polymethylmethacrylate once hardened, is high resistance for compression forces which is extremely useful in vertebroplasty procedure [8]. It not only provides structural stability by means of internal trabecular stabilization and prevents further compression, but also reduces the activity of pain-sensitive periosteal nerves [2] Besides its mechanical property, it also induces direct chemical toxicity and thermal necrosis by an exothermic reaction (80-90

Acknowledgment: The authors declare that they have no conflict of interest.

Authors Contribution: All authors have read and approved the manuscript submitted in this journal. All authors contributed equally to this work mentioned below: Study conception and design, Acquisition of data, Analysis and interpretation of data, Drafting

\section{References}

1. Rosian K, Hawlik K, Piso B (2018) Efficacy Assessment of Radiofrequency Ablation as a Palliative Pain Treatment in Patients with PainfulMetastatic Spinal Lesions: A Systematic Review. Pain Physician 21(5): 467-476.

2. Kam NM, Maingard J, Kok HK, Ranatunga D, Brooks D, et al degrees C) to nerve endings [2].

RFA and vertebroplasty are independently beneficial in reducing the pain in spinal metastasis [9]. Few studies report the combination of RFA and vertebroplasty to have a potential synergistic effect on reducing the pain in spinal metastasis $[2,10]$. The reports of the combination of both RFA and vertebroplasty in a single session are scarce [10].

In our patient, the tumor was located in the vertebral body L1 with progressively worsening pain. MRI showed a well demarcated lesion with low signal on both T1 and T2 weighted images with an intact posterior wall, prone to pathologic fracture. Surgery is the standard of care for vertebral pathologic fracture complicated by spinal instability [11]. In this case there was little loss of spinal integrity due to the intact posterior wall, this is a prerequisite for this technology. The Metastatic Spine Disease Multidisciplinary Working Group Algorithms recommends vertebral augmentation and RFA as first-line palliation of pain related to stable vertebral pathologic fracture [11]. In a retrospective series by Wallace et al. [6] the combination RFA and vertebral augmentation achieved clinically significant decrease of pain scores at both 1-week (mean, $3.9 \pm 3.0$ ); median, 3.25; P < 0.0001 ) and 4-week (mean, $2.9 \pm 3.0$; median, 2.75; P < 0.0001) follow-up. S. Bagla et al. [3] in their prospective study found that RFA with or without vertebral augmentation is a safe, effective and durable treatment. The major concern of most prospective studies was the lownumber of included patients and also the short follow up period. Thisis challenging in advanced spine metastasis due to high morbidity and mortality rates [1]. The National Comprehensive Cancer Network ontheir guideline's version 2.2019 for Adult Cancer Pain also has put RFA as treatment modality for control of local bone pain [12]. However, in the term of cost effectiveness and cost efficiency, an evaluation of the effect of RFA alone in comparison to RFA in combination with vertebroplasty for the treatment of painful vertebralmetastasis should be conducted in large number of cases most likely involving multiple centers.

manuscript, Critical revision.

\section{Source(s) of support: Nil}

Conflicting Interest: Nil

Acknowledgement: Nil

(2017) Combined Vertebral Augmentation and Radiofrequency Ablation in the Management of Spinal Metastases : an Update. Current Treatment Options in Oncol 18(12): 74

3. Bagla S, Sayed D, Smirniotopoulos J, Brower J (2016) Multicenter Prospective Clinical Series Evaluating 
Radiofrequency Ablation in the Treatment of Painful Spine Metastases. Cardiovasc Intervent Radiol 39(9): 1289-1297.

4. Chow E, Harris K, Fan G, Tsao M, Sze WM (2007) Palliative radiotherapy trials for bone metastases: A systematic review. J Clin Oncol 25:1423-1436.

5. Zerlauth J, Meuli R, Dunet V (2017) Renal cell carcinoma metastasis involving vertebral hemangioma: dual percutaneous treatment by navigational bipolar radiofrequency ablation and high viscosity cement vertebroplasty. BMJ Case Rep 2016-2018.

6. Wallace AN, Greenwood TJ, Jennings JW (2015) Radiofrequency ablation and vertebral augmentation for palliation of painful spinal metastases. Journal of NeuroOncology. Springer US 124: 111-118.

7. Dupuy DE, Hong R, Oliver B, Goldberg SN (2000) Radiofrequency Ablation of Spinal Tumors: Temperature Distribution in the Spinal Canal. AJR Am J Roentgenol
Journal of Medical Case Reports and Case Series 1 ISSN: 2692-9880 175(5):1263-1266

8. Laredo J, Chiras J, Kemel S, Taihi L, Hamze B (2018) Vertebroplasty and interventional radiology procedures for bone metastases. Joint BoneSpine 85: 191-199.

9. Grönemeyer DHW, Schirp S, Gevargez A (2002) Image-guided Radiofrequency Ablation of Spinal Tumors: Preliminary Experience With anExpandable Array Electrode. Cancer J 8(1): 33-39.

10. David E, Kaduri S, Yee A, Chow E, Sahgal A, et al. (2017) Initial Single Center Experience: radiofrequency ablation assisted vertebroplasty and osteoplasty using a bipolar device in the palliation of bone metastases. Ann Palliat Med 6(2): 118-124.

11. Wallace AN, Robinson CG, Meyer J, Tran ND, Gangi A, et al. (2015) The Metastatic Spine Disease Multidisciplinary Working GroupAlgorithms. Oncologist 20(10): 1205-1215.

12. NCCN (2019) Guidelines Adult Cancer Pain. 